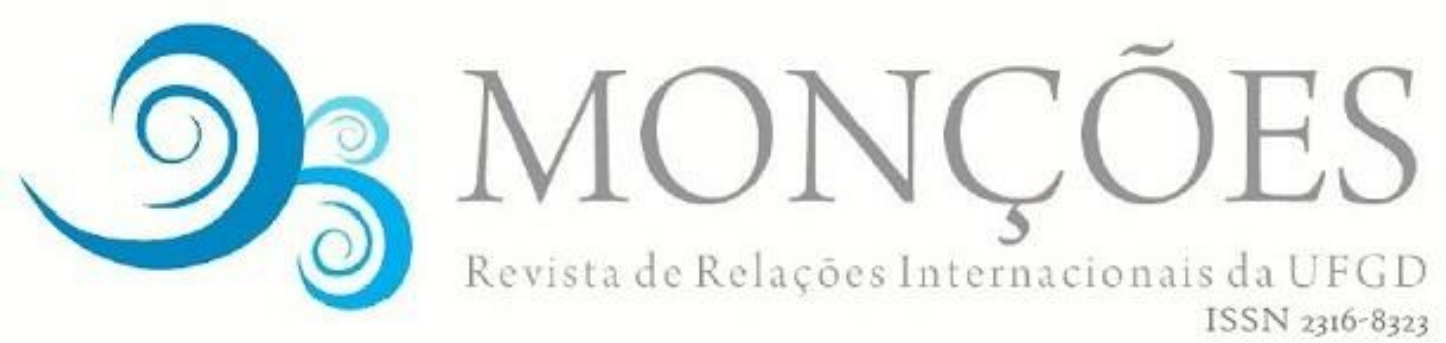

\title{
TENDÊNCIAS E CONTRADIÇÕES DA INFLUÊNCIA CORPORATIVA NA AGENDA AGROALIMENTAR DAS NAÇÕES UNIDAS
}

TIAGO MATOS DOS SANTOS

Mestre em Relações Internacionais - Universidade Federal da Bahia (PPGRI-UFBA) com bolsa da Fundação de Amparo à Pesquisa do Estado da Bahia (FAPESB). Bacharel em

Humanidades com concentração em Relações Internacionais (IHAC-UFBA). Membropesquisador do Globalização da Política (GLOPOLI) e do Laboratório de Análise Política Mundial (LABMUNDO). Contato: tiagomatosbr@gmail.com ORCID: https://orcid.org/0000-

$\underline{0002-4543-8706}$

RESUMO: Desde a virada do milênio, a participação das corporações transnacionais e entidades filantrópicas na agenda de desenvolvimento e direitos humanos das Nações Unidas (ONU) tem sido crescente. Além do Pacto Global, novos espaços de cooperação e diálogo entre empresas e agências da ONU foram criados ou estão sendo discutidos. Na governança global da agricultura e alimentação, essa interação, além de notável, apresenta perfil e dinâmicas próprias, resultado do caráter estratégico que tais parcerias assumiram na agenda tanto das corporações quanto das organizações internacionais (Ols). $\mathrm{O}$ artigo, portanto, discute como tem se dado a participação e a influência das corporações na governança agroalimentar das Nações Unidas. Nesta perspectiva, apresentam-se especificamente as interações políticas e institucionais entre as transnacionais ligadas ao agronegócio e três organizações/programas do sistema ONU - a Organização das Nações Unidas para Alimentação e Agricultura (FAO), o Fundo Internacional de Desenvolvimento Agrícola (FIDA) e o Programa Alimentar Mundial (PAM), expondo as razões e os mecanismos responsáveis pela aproximação entre esses atores, ao tempo que destaca algumas das contradições presentes nesta relação. Por fim, mapeia desafios analíticos que se interpõem à abordagem das contradições observadas na intersecção entre atores privados e a governança global agroalimentar.

PALAVRAS-CHAVE: Corporações; Governança Global; Segurança Alimentar; Nações Unidas; Neoliberalismo.

\section{TRENDS AND CONTRADICTIONS OF THE CORPORATE INFLUENCE ON THE UNITED NATIONS AGRIFOOD AGENDA}

\begin{abstract}
Since the millennium turn, the participation of transnational corporations and philanthropic entities in the UN development and human rights agenda has been increasing. Besides the Global Compact, new spaces for cooperation and dialogue among enterprises and UN agencies were designed or are currently being proposed. In the global governance of agriculture and food, this interaction is notable and presents its own profile and dynamics, which is the result of the strategic nature assumed by these partnerships in the agenda of both corporations and international organizations (IOs). This article discusses how the influence of corporations on the UN agrifood
\end{abstract}


agenda has been occurring. In this perspective, it focuses on the political and institutional interactions between agribusiness transnational corporations and three organizations/programs of the UN system - the Food and Agriculture Organization (FAO), the International Fund for Agriculture and Development (IFAD) and the World Food Program (WFP), by exposing the reasons and mechanisms responsible for the approximation of these actors, by the time that highlights some of the contradictions that emerge from this relationship. Finally, it maps some of the analytical challenges that poses to the observation of the contractions in the intersection between private actors and the global agrifood governance.

KEYWORDS: Corporations; Global Governance; Food Security; United Nations; Neoliberalism.

\section{Introdução}

As crises iniciadas na década de 1970 impuseram profundas mudanças na economia e política internacional, assim como permitiram a aceleração de algumas dinâmicas. O fim do Pacto Fordista deu início à fragilização das camadas médias nos países do hemisfério norte, acentuou a vulnerabilidade dos Estados periféricos sob a égide dos programas de ajustes estruturais (Structural Adjustment Policies SAPs), e ficou posteriormente exemplificado no Consenso de Washington e na onda liberalizante que varreu as antigas economias planificadas nos anos 90s. Este novo momento histórico repercutiu diretamente na agenda das organizações internacionais públicas integrantes do sistema das Nações Unidas, tanto do ponto de vista orçamentário, quanto no que dizia respeito à sua legitimidade para o cumprimento das funções para as quais haviam sido criadas, sob a liderança hegemônica estadunidense.

Entre a década de 1990 e a virada do milênio, devido em parte ao fim da bipolaridade, temas como conflitos étnicos/civis, assistência humanitária, crises ambientais, direitos humanos, refugiados, epidemias, desenvolvimento social, etc., passaram a ganhar enorme atenção da comunidade internacional. O ganho de espaço obtido por essas pautas no interior dos debates políticos foi acompanhado também por certa pressão em favor da integração dos chamados atores não-estatais às agendas oficiais das organizações internacionais, particularmente no que se refere à participação das Organizações não-governamentais (ONGs), dos movimentos sociais, das fundações filantrópicas e das grandes corporações transnacionais (CTNs). 
$\mathrm{Na}$ agenda agroalimentar e nutricional, esse movimento esteve marcado pelo entrelaçamento do paradigma produtivista agrícola com os ganhos de representatividade dos atores privados na nova ordem global, o que, em termos práticos, se traduziu na abertura de novos espaços de diálogo e atuação para as CTNs nas instâncias deliberativas e fóruns políticos da ONU sobre alimentação e agricultura. A Conferência sobre o Meio Ambiente (Rio 92) foi a primeira síntese e palco desse processo (RICHTER, 2004), mas não a última. De lá para cá, sucessivas tentativas de agregar empresas e agentes financeiros globais às atividades das instituições da governança agroalimentar veem sendo pensadas por lideranças políticas, governos, think tanks e altos-funcionários da ONU, sob o argumento da inevitabilidade dessas parcerias para o endereçamento dos desafios alimentares do presente e do futuro (FONTOURA, BHARUCHA \& BOHM, 2016).

Mais recentemente, impulsionados por fatores diversos como os impactos da (in)segurança alimentar nas políticas de desenvolvimento humano e na estabilidade das zonas de conflito; nos efeitos das mudanças climáticas e os prognósticos de crescimento da população mundial até 2050; e, não menos importante, pelos desafios para o combate a fome revelados pela crise alimentar de 2007/2008, uma série de publicações vem buscando analisar sistematicamente as transformações operadas na governança agroalimentar e nutricional global. Os trabalhos de John Shaw (2007) e Nora McKeon (2009) são parte deste processo e recontam, de um lado, a trajetória histórica das políticas de segurança alimentar e nutricional na agenda internacional; e do outro, as contradições da abertura dessa agenda aos atores da sociedade civil, particularmente no contexto da Cúpula Mundial da Alimentação (1996) e da construção das Diretrizes sobre o Direito à Alimentação (2004).

Neste artigo, busca-se analisar particularmente a influência das corporações transnacionais no interior de três organizações internacionais da ONU e de suas respectivas políticas para agricultura e alimentação. Pretende-se apontar alguns dos elementos que marcam essa relação, assim como suas contradições. Os métodos empregados na pesquisa que originou esse artigo consistiram no levantamento e análise de documentos disponibilizados pelas próprias Ols, relatórios produzidos por entidades da sociedade civil e, naturalmente, na bibliografia já acumulada sobre o 
tema. Dada a intrínseca complexidade, amplitude e as inúmeras possibilidades de abordagem do tema, o texto se restringe a analisar a relação das corporações transnacionais com três principais organismos da governança agroalimentar global, particularmente no transcurso dos últimos 10 anos (2008-2018). São elas: a Organização das Nações Unidas para Alimentação e Agricultura $(F A O)^{1}$, o Fundo Internacional para o Desenvolvimento Agrícola $\left(\right.$ FIDA) ${ }^{2}$ e o Programa Alimentar Mundial (PAM) $)^{3}$.

$\mathrm{O}$ artigo se divide em três sessões principais. Na primeira, aborda-se o panorama histórico da relação entre a ONU e as corporações transnacionais para, em seguida, analisar essa dinâmica à luz das ferramentas conceituais oferecidas por teóricos dos chamados Estudos Críticos da Globalização, que tendem a analisar a governança global sob o prisma de seu caráter essencialmente neoliberal. $\mathrm{Na}$ segunda sessão, apresentam-se os eixos de análise através do qual se observa a interação entre as corporações transnacionais e as organizações internacionais vinculadas à agenda agroalimentar da ONU, assim como os fatores que atravessam esse processo, como a crescente financeirização e concentração dos sistemas alimentares pelo capital transnacional do agronegócio. Finalmente, na terceira sessão, discutem-se alguns dos aspectos considerados mais relevantes da relação entre as CTNs e as agências das Nações Unidas, destacando as modalidades através das quais esses atores costumam atrelar suas respectivas agendas de atuação e, posteriormente, as problemáticas e contradições a que essas parcerias estão associadas.

1 A Organização das Nações Unidas para Alimentação e Agricultura (UN Food and Agriculture Organization) é a principal plataforma da ONU voltada à erradicação da fome, pobreza rural, fomento à sustentabilidade na produção agrícola e garantia da segurança alimentar dos povos. A organização, fundada no pós-guerra (1945), tem sede em Roma, Itália, agrega 197 países e atualmente é dirigida pelo brasileiro José Graziano (2012 - atual). A FAO possui alguns órgãos internos que são compartilhados com outras agências, como o Comitê do Codex Alimentarius (FAO/OMS) e o Conselho de Segurança Alimentar (FAO/FIDA/PAM).

${ }^{2}$ Fundo Internacional das Nações Unidas para o Desenvolvimento Agrário (UN International Fund for Agricultural Investiment) foi fundado em 1977 como um dos desdobramentos da Conferência Mundial da Alimentação de 1974. Entre seus principais objetivos está o financiamento de projetos de desenvolvimento agrícolas em países em desenvolvimento, aumentando as capacidades das populações rurais pobres de produzirem alimento.

3 O Programa Alimentar Mundial da ONU (UN World Food Program - WFP) surgiu em 1961 e é a maior organização humanitária do mundo. Atuando principalmente na oferta emergencial de alimentos a populações afetadas por conflitos civis, desastres ambientais e profundas crises econômicas - fatores causadores de insegurança alimentar. 


\section{Responsabilidade como legitimação: um panorama teórico-histórico da} integração das corporações transnacionais ao Sistema das Nações Unidas

A história da relação entre a ONU e as CTNs acompanha o ganho de importância político-econômica que estas últimas passaram a acumular ao longo da segunda metade do século XX. De acordo com Aragão (2010), essa relação está marcada por dois principais períodos: um de natureza "conflitiva", e o outro, de natureza, chamemos, de "conciliativa". Durante a primeira fase, entre as décadas de 1960 e 1970, a ONU sediou mobilizações para a construção de um Código de Conduta vinculante para regulação das atividades das corporações transnacionais. A iniciativa era conduzida por países da periferia, como o Chile do então presidente socialista, Salvador Allende, os quais, naquela época, já denunciavam violações de direitos humanos e participação em golpes políticos envolvendo empresas multinacionais ${ }^{4}$. Com o advento das crises econômicas da década de 1980, a proposta do código de conduta para as CTNs foi perdendo força política. Entre as principais razões para isso, encontram-se 0 endividamento externo e os constrangimentos estruturais que a mobilidade dos Investimentos Externos Diretos (IEDs) e dos capitais financeiros passavam a assumir, principalmente no contexto de economias periféricas submetidas ao processo de reorganização das finanças globais e de aprofundamento das políticas neoliberais. O encerramento dos debates em torno da proposta, em 1992, foi seguido de um novo momento, primeiro com a eleição do então secretário geral Boutros Boutros-Ghali (1992-1996), mas, sobretudo, com seu sucessor, Kofi Annan (1997-2007).

Com Annan, a ONU realizou uma extensa abertura em sua relação com às forças e mecanismos regulatórios do Mercado. Tal agenda se destacou pela busca de parcerias com o setor privado, pela formação de espaços institucionais de diálogo com as empresas e por um profundo comprometimento da instituição com o tema da responsabilidade social corporativa (ARAGÃO, 2010, p.87). Duas razões geralmente apontam para a explicação dessa dinâmica, uma de natureza financeira, outra de natureza ideológica (GREGORATTI, 2010, p.192). A primeira delas associa o

\footnotetext{
${ }^{4}$ Um desses golpes, apoiado pela International Telephone and Telegraph (ITT), uma multinacional da comunicação sediada nos EUA, culminou na deposição do próprio presidente chileno, Salvador Allende, em 1973.
} 
aprofundamento dos vínculos da ONU com as empresas aos problemas ocasionados pela dependência financeira das Ols em face dos Estados financiadores. Como explica Aragão (2010, p.61), para se legitimar diante de seus financiadores, as Ols sempre buscaram incorporar, em alguma medida, as demandas desses atores em sua atuação. A outra explicação, de natureza ideológica, teria a ver com o próprio conteúdo das reformas propostas por Kofi Annan, sua presença constante em espaços da elite corporativa global, como o Fórum Econômico de Davos, e sua idealização de mecanismos que integrassem as empresas na agenda social de direitos humanos e desenvolvimento (MARTENS, 2014, p.8).

Entre os mecanismos idealizados pelo então secretário geral, os mais conhecidos são os Objetivos de Desenvolvimento do Milênio (ODMs) e o Pacto Global, ambos lançados em 2000. No caso particular do Pacto Global, gestado sob direção de John Ruggie ${ }^{5}$, a iniciativa buscava forjar um novo pacto político entre as demandas sociais e as forças econômicas do capitalismo, centrado, desta vez, no papel ativo e voluntário das empresas (BULL e MCNEILL, 2010, p.107). A conversão ao novo paradigma de relacionamento com os mercados, a partir dos anos 2000 , esteve presente na celebração de ambas as iniciativas à cooperação com as CTNs, ao estabelecimento de uma agenda programática e pragmática de metas para o desenvolvimento, no fomento a parcerias-público-privadas (PPPs) como plataforma de combate à pobreza, no incentivo à abertura aos investimentos e ao comércio entre os países periféricos e, principalmente, em um modelo de governança assentado em mecanismos flexíveis e voluntários para a integração das empresas no tema dos direitos humanos (ARAGÃO e SANTOS NETO, 2015).

A literatura "clássica" costuma abordar o tema da governança global com base em aspectos relacionados às mudanças nos níveis de decisão, na natureza da autoridade e na interrelação entre fatores (ROSENAU, 1992). No entanto, para

5 John Ruggie é um proeminente teórico de Relações Internacionais, professor na Havard Kennedy School, onde atua principalmente nos temas de Empresas e Direitos Humanos. Na ONU, Ruggie foi nomeado por Kofi Annan para planejar a formulação e implementação do Pacto Global e dos Objetivos de Desenvolvimento do Milênio entre 1997 e 2001. Em sua produção acadêmica, é conhecido principalmente pelo conceito de Liberalismo Enraizado (Embedded Liberalism), presente em sua obra International Regimes, Transactions and Change: embedded liberalism in the postwar economic order (1982). 
compreender as contradições da relação entre as organizações internacionais e os atores do capital transnacional, julga-se necessário, antes, apontar para as profundas mudanças na ordem internacional dos últimos 40 anos. Essas mudanças referem-se, basicamente, ao papel da globalização e das elites político-econômicas que a governam.

Conforme argumenta Robert Cox, a globalização, originada do processo de internacionalização dos capitais, da produção e das finanças, não apenas forçou a competição fiscal e tributária entre países, regiões e unidades subnacionais, como também levou a um processo progressivo de deslocamento da autoridade econômica - do internacional para o global (COX, 1993, p.260). Para Stephen Gill (1995), esse fenômeno tem sido liderado por um ascendente bloco histórico transnacional, que inclui em sua composição, além de membros do alto-escalão dos setores público e privado, multimilionários e suas entidades representativas, as corporações transnacionais ${ }^{6}$. Para Gill, o objetivo deste bloco histórico é a expandir um modelo civilizacional ancorado em uma visão economicista, imediatista, estreita, autoritária e ecologicamente irresponsável de mundo, a que ele intitula Market Civilization (GILL, 1995, p.399; 1997, p.14). A expansão da civilização de mercado pressupõe, para o efetivo controle e subjugação da democracia às forças do capitalismo, mudanças de natureza regulatória, de modo a tornar o Estado e os instrumentos jurídicos públicos mecanismos de blindagem do processo de acumulação do capital e dos efeitos contraditórios que o acompanham. Trata-se do que Gill chama de Neoconstitucionalismo (GILL, 1995).

Nas organizações internacionais, responsáveis, entre outras funções, pela incorporação, produção e legitimação das normas que refletem os interesses, valores e objetivos do bloco histórico hegemônico (COX, 1983), a expansão da

\footnotetext{
${ }^{6}$ A noção de "bloco histórico transnacional" aqui empregada deriva de uma releitura, por Robert Cox, do conceito de "bloco histórico", empregado pelo filósofo político italiano, Antônio Gramsci (18911937). Stephen Gill oferece uma descrição detalhada de ambos conceitos, descrevendo o bloco histórico como "uma congruência entre forças materiais, instituições e ideologias... [...] ligação orgânica entre a estrutura e a superestrutura, e organizado ao redor de um conjunto de ideias hegemônicas que compõem a 'ideologia dominante' (GILL, 1986, p.210, tradução nossa), enquanto revela que o bloco histórico transnacional é composto por "mais de uma classe [...], sua base é mais orgânica (por exemplo, ancorada nos interesses materiais e nos quadros de pensamento ou visões e entendimentos do mundo social por um número de classes e outros grupos) e envolve instituições governamentais e da sociedade civil de um número de países, incluindo estados periféricos" (GILL, 1986, p.211, tradução nossa).
} 
market civilization é perceptível sob o prisma da conversão neoliberal das agendas de desenvolvimento e direitos humanos, que têm adotado um enfoque cada vez mais pragmático, flexível, programático, minimalista, voluntário e ancorado em mecanismos de automonitoramento, a fim de se ajustarem ao vocabulário do Mercado e à pressão neoliberal por desregulação e privatização (ARAGÃO e SANTOS, 2017). A imposição desse receituário político-ideológico é didática no sentido de explicar a progressiva substituição dos Tratados e Convenções Internacionais vinculantes por Princípios-Guia e Códigos Voluntários de "Boa Governança", nos marcos de uma governança global que não somente é incapaz de constranger os centros políticos e econômicos, mas que empodera os seguimentos ligados ao capital transnacional.

Efeito direto das contradições da governança global neoliberal é o descompasso, apontado por Aragão, entre o mencionado empoderamento das CTNs no âmbito das Nações Unidas, e o descumprimento por elas mesmas de prerrogativas mínimas de respeito aos direitos humanos. Como descreve: "o processo acelerado de globalização econômica não foi acompanhado por uma globalização da política que implicasse na responsabilidade em direitos humanos dos atores que operam transnacionalmente" (ARAGÃO, 2010, p.145). Com base nessa constatação, argumenta-se que as corporações transnacionais buscam legitimar sua autoridade via associação com as políticas agroalimentares adotadas no âmbito de algumas das principais organizações e agências da ONU, mesmo não demonstrando interesse em assumir os riscos e responsabilidades inerentes à complexidade social imposta pela globalização do capital, das quais as próprias CTNs são representantes.

\section{O poder corporativo e a agenda agroalimentar das organizações internacionais}

É difícil precisar o momento em que as CTNs passaram a exercer influência na agenda agroalimentar das organizações internacionais integrantes do sistema ONU. Se analisadas as décadas de 1950 e 1960, quando o paradigma produtivista da Revolução Verde dominava as discussões sobre o desenvolvimento rural nas 
instituições internacionais, já é possível perceber certo otimismo por parte das agências onusianas com o modelo de agronegócio americano - baseado na agricultura mecanizada, altamente demandante de insumos químicos, voltada à exportação e atrelada aos grandes bancos de crédito agrícola - como programa de combate à fome mundial. Com a transnacionalização dos capitais agrícolas, cujas condições foram preparadas pelas políticas neoliberais sobre a agricultura dos países do Sul ${ }^{7}$, as Ol's passaram a ser tanto palco de legitimação, quanto de conflito ao redor do modelo de desenvolvimento rural proposto pelo regime alimentar corporativo (McMICHAEL, 2016).

Abordando o contexto de alguns dos principais processos de concertação da agenda global de governança agroalimentar nas últimas décadas, Nora Mckeon (2009) destaca a capacidade das empresas penetrarem nos espaços públicos de tomada de decisão e de influenciarem em seus resultados. Tal habilidade reflete o peso estrutural das corporações agroalimentares no âmbito das finanças e da economia global. Favorecidas pela desregulação dos mercados financeiros no Centro e na Periferia, atualmente essas corporações estão na linha de frente do processo de financeirização da agricultura. Os investimentos especulativos em commodities agrícolas praticamente dobraram entre as primeiras décadas do século XXI, saltando de US\$ 65 em 2006, para US\$126 bilhões de dólares em 2011 (CLAPP e ISAKSON, 2018, p.4). Parte dessa dinâmica se deve à criação, por parte de empresas como a Cargill, de uma série de produtos financeiros ancorados nas principais commodities agrícolas comercializadas no mercado internacional. A financeirização da agricultura, além de subtrair o valor sociocultural dos alimentos, favorece a instabilidade de preços e a recorrência de crises alimentares, como as experimentadas em 2008 e 2011.

\footnotetext{
${ }^{7} \mathrm{O}$ receituário neoliberal de políticas sobre a agricultura e alimentação dos países do Sul incluiriam: "o fim do incentivo público à agricultura familiar nos países periféricos; às barreiras tarifárias aos altamente subsidiados produtos agrícolas norte-americanos e europeus; o estímulo à eliminação das políticas nacionais de estoques de sementes e grãos de primeira necessidade; a abertura do mercado agrícola e fundiário a consórcios estrangeiros, etc. Essas políticas, além de terem favorecido a penetração de capitais estrangeiros na agricultura e de terem reforçado a colonial matriz agroexportadora de alguns países periféricos, teve como resultado, em muitos casos, a reversão da base de abastecimento nacional e a consequente transformação de alguns desses países, antes exportadores de alimentos ou autossuficientes em determinadas culturas, em importadores alimentícios e/ou dependentes do envio de ajuda alimentar internacional para a satisfação das necessidades alimentares e nutricionais da população mais pobre" (ARAGÃO e SANTOS, 2017, p.67).
} 
Se o poder das corporações sobre o mercado financeiro chama a atenção, seu controle sobre as cadeias de distribuição de alimentos é ainda mais preocupante. Dados apontam que apenas três corporações controlam 57\% do comércio mundial de sementes de milho, e $55 \%$ das sementes de soja em circulação (ECONEXUS, 2013). Outros números indicam que apenas 4 companhias controlam mais de $80 \%$ do comércio mundial de chá e $40 \%$ de todo o comércio de café (DE SHUTTER, 2010, p.2). Entre as redes globais do varejo, o domínio da cadeia por um punhado de grandes demandantes tem exercido enorme pressão sobre o preço dos alimentos ofertados pelos produtores rurais, levando a um progressivo rebaixamento da renda e das condições de vida e produção no campo. Oliver De Shutter, exrelator da ONU para o Direito à Alimentação, cita que, de 1997 a 2002, enquanto o preço do grão de café ofertado por produtores rurais aos supermercados caiu em cerca de $80 \%$, entre as corporações do varejo a redução foi de apenas $27 \%$, ao passo que os lucros de redes como Starbucks e Nestlé cresceram, respectivamente, entre $41 \%$ e $20 \%$ (DE SHUTTER, 2010, p.2).

As condições assinaladas nos últimos parágrafos explicam alguns dos fatores-chave por trás da centralidade assumida pelas empresas multinacionais na agenda de alguns organismos internacionais que lidam com agricultura e alimentação. Nas próximas sessões, será possível visualizar parcialmente como essa dinâmica ocorre. Antes, porém, cabe fazer algumas considerações conceituais sobre os mecanismos de poder utilizados pelas corporações afim de influenciar as políticas agroalimentares no âmbito das Nações Unidas. Trata-se do "como" da questão. Neste sentido, a abordagem de Jennifer Clapp e Doris Fuchs (2009) oferece interessantes eixos de análise para refletir sobre essa relação.

De acordo com as autoras, as corporações transnacionais exercem três principais formas de poder sobre a agenda agroalimentar global: instrumental, estrutural e discursivo. Em linhas gerais, o poder instrumental diz respeito a capacidade das CTNs exercerem pressão ou influência sobre determinada agenda política com o objetivo de alterar seu conteúdo ou resultado (CLAPP e FUCHS, 2009, p.9). Na definição das autoras, essa modalidade de exercício de poder envolve recursos organizacionais, humanos e financeiros, sendo mais abertamente notável na forma como as empresas acessam diretamente os agentes e espaços 
públicos de decisão mediante diferentes abordagens, entre elas, as doações de campanha (eleitoral), por exemplo.

$\mathrm{Na}$ governança agroalimentar da ONU, o Comitê do Codex Alimentarius, departamento conjunto da FAO e da Organização Mundial da Saúde (OMS) responsável pela produção de normas sobre rotulagem, parâmetros sanitários e fitossanitários da comercialização de alimentos, etc., exemplifica como as corporações exercem poder instrumental ${ }^{8}$. Nos anos 2000, a comissão de rotulagem do órgão contava com 50 membros da sociedade civil, 35 dos quais representavam a agroindústria. Delegações como a canadense, por exemplo, costumavam hospedar um elevado número de representantes das corporações alimentícias entre seus membros, entre os quais, executivos da Monsanto, Nestlé e Kraft (SMYTHE, 2009, p.89). As razões pelas quais as corporações decidem influenciar diretamente na composição das delegações governamentais em comitês como o Codex são óbvias: garantir assento, participação e influênciar na dinâmica desses organismos tem caráter estratégico, dada a sensibilidade das CTNs ao temas tratados nesses organismos.

Enquanto o poder instrumental diz respeito à capacidade de exercício da influência corporativa através de mecanismos diretos, o poder estrutural refere-se à capacidade adquirida pelas corporações de controlar e delimitar o espaço de ação política dos Estados e das Ols a partir da posição que ocupam nas economias nacionais e global, de modo a constranger o conteúdo, a construção e a aplicação de mecanismos de governança (CLAPP e FUCHS, 2009, p.9). Esta é uma noção que guarda clara semelhança com o que Stephen Gill chama de Neoliberalismo Disciplinar, ao se referir à forma de governança político-econômica articulada em torno da civilização de mercado e do controle sobre os governos, as relações humanas e a vontade pública. Na contemporaneidade, o tipo de influência e pressão exercida pelas agências de avaliação de risco sobre as políticas macroeconômicas dos Estados é um exemplo didático de poder estrutural do capital global.

\footnotetext{
${ }^{8}$ Apesar de possuírem praticamente o mesmo nome, o referido Comitê se diferencia do Codex Alimentarius (do Latin, "código alimentar") no sentido de que, enquanto o primeiro é um organismo internacional em atividade desde 1963, o último diz respeito aos códigos, padrões, diretrizes e recomendações que governam a qualidade e segurança da produção e comercialização de alimentos internacionalmente.
} 
O disciplinamento da governança global agroalimentar e nutricional pelo poder estrutural das corporações transnacionais reflete em grande medida 0 sucesso e o fracasso, o alcance e os limites de determinadas agendas e demandas. A elaboração e negociação dos princípios para Investimentos Agrícolas Responsáveis (Principles for Responsible Investiments in Agriculture and Food Systems - RAl), por exemplo, demarcou uma mudança de postura dos países europeus e africanos quanto a importância dos direitos humanos e dos pequenos produtores rurais, outrora defendidos por suas delegações em ocasião da negociação das Diretrizes sobre Governança da Terra, em 2012 ${ }^{9}$. O peso das questões que envolvem investimentos agrícolas para as economias de ambos os continentes - principalmente o africano -, levou a que Europa e África atuassem de forma muito mais alinhada com os interesses do setor privado durante a aprovação dos RAI, em 2014 (McKEON, 2017).

O poder discursivo, por seu turno, refere-se à capacidade das corporações de construir discursos ancorados em elementos como expertise e good practices, capazes de penetrar os fóruns públicos de governança global, forjar consensos e adesão em torno de quadros regulatórios (que podem ser de 'não-regulação') que atendam aos seus respectivos interesses político-financeiros. A dimensão discursiva do poder corporativo é, nestes termos, parte indissociável do processo de legitimação da autoridade privada sobre os sistemas políticos e alimentares (CLAPP e FUCHS, 2009).

Um exemplo de exercício do poder discursivo das corporações transnacionais é seu apoio à narrativa de que "a agricultura precisa de investimentos". Trata-se de uma estratégia que, principalmente após a última crise alimentar mundial, tem sido largamente empregada com o objetivo de formatar o debate público em favor de um paradigma de segurança alimentar que, a despeito de critérios como regularidade, renda, disponibilidade, qualidade e valor nutricional dos alimentos, coloca na expansão do modelo da agroindústrias produtoras de monoculturas de exportação, no mercado internacional e no Acordo sobre Agricultura (Agreement on Agriculture - AoA) da Organização Mundial do Comércio

\footnotetext{
${ }^{9}$ Diretrizes Sobre Governança Responsável da Posse de Terras, Recursos Pesqueiros e Florestais, documento adotado na 37aㅗ sessão especial do Conselho de Segurança Alimentar, em maio de 2012.
} 
(OMC) a responsabilidade sobre a materialização do direito à alimentação. O casamento entre o poder discursivo das corporações agroalimentares e sua ratificação via paradigma hegemônico de segurança alimentar, é atestado por Williams quando observa que "[...] a ligação entre interesse e compromisso normativo é fortalecida através do apoio explícito dado ao quadro de segurança alimentar pelos representantes das corporações do agronegócio e consultores da indústria"(WILLIAMS, 2009, p.169, tradução nossa).

A institucionalização desse framework de segurança alimentar no âmbito de organizações internacionais como a FAO, com substancial apoio das corporações transnacionais e governos, fortalece no plano discursivo a falácia que rotula a fome como um problema de ordem simplesmente quantitativa (uma deficiência de produtividade) - e não reflexo das incoerências do regime alimentar capitalista (McMICHAEL, 2014). Além disso, conduz à naturalização do Mercado como espaço de realização das necessidades alimentares e nutricionais - a despeito de seus impactos sociais e ambientais sobre as comunidades de pequenos produtores, a agricultura e os recursos naturais; e, finalmente, aprofunda a marginalização de formas alternativas de produção, consumo e distribuição de alimentos, como propõe, por exemplo, o projeto de Soberania Alimentar defendido por redes de movimentos sociais rurais (ALEM et al, 2015; ROSSET, 2003; VIEIRA, 2008, McMICHAEL, 2014).

A categorização das modalidades de exercício do poder corporativo sobre a agenda agroalimentar, como estabelecida por Clapp e Fuchs (2009), contribui para a formulação de uma visão panorâmica sobre a interação entre os capitais transnacionais e as agências públicas globais. Em prática, no entanto, essa relação apresenta dinâmicas e características variadas. De acordo com o espaço disponível e os objetivos deste artigo, na próxima sessão discutem-se cinco principais aspectos que se sobressaem na interação institucional entre as CTNs e agências como a FAO, o FIDA e o PAM. Em seguida, analisa-se algumas das contradições empíricas e potenciais que permeiam essa dinâmica, tendo como ponto de partida as políticas desenvolvidas por essas instituições ao longo dessas primeiras décadas do século $\mathrm{XXI}$. 


\section{A relação entre as corporações transnacionais $e$ as políticas agroalimentares das Nações Unidas}

Como dito anteriormente, existem variadas formas de interação e mecanismos através dos quais as corporações influenciam a agenda de organizações internacionais. Richter (2004, p.45) aponta para cinco delas, que são: 1) fundraising - aceitação ou requerimento de doações financeiras pelas Ols; 2) arranjos coregulatórios voluntários, principalmente para a confecção e/ou difusão de códigos de conduta; 3) projetos de responsabilidade social corporativa; 4) negociação de produtos/serviços a preços abaixo de mercado; e 5) contratos para a oferta de serviços públicos. Ao longo das próximas páginas, ainda que não englobe necessariamente às cinco categorias, será possível perceber alguns desses mecanismos de relacionamento institucional no que diz respeito às relações entre as corporações transnacionais e as agências abordadas aqui.

\subsection{A influência corporativa na agenda agroalimentar da ONU: aspectos relevantes}

O primeiro aspecto relevante na interação entre as CTNs e as Ol's da governança agroalimentar é o aumento expressivo da contribuição financeira corporativa aos orçamentos das organizações. Trata-se de uma tendência que não se restringe às agências de alimentação e agricultura, mas ao conjunto do sistema ONU, o qual, só em 2013, recebeu US\$3.3 bilhões de dólares em doações do setor privado (ADAMS e LUCHSINGER, 2015, p.1). O caso do Programa Alimentar Mundial é um dos mais emblemáticos. Entre as doações privadas recebidas pelo Programa de 2009 a 2011, as empresas foram responsáveis por pelo menos $43 \%$ dos recursos, sendo o restante repartido entre doadores individuais e ONGs. Entre o ano de 2014 e fevereiro de 2018, as doações privadas ao orçamento do organismo contabilizaram US $\$ 401,994,156$, sendo o setor privado atualmente responsável pela $11^{\circ}$ posição na lista de doadores do Programa, que conta com outros 134 países e instituições (WFP, 2018). Embora a quantia represente apenas pouco mais de 10\% de seu orçamento geral, é interessante perceber a ascensão que as doações privadas trilharam no orçamento do PAM desde 1998, quando passaram a ser 
divulgadas ${ }^{10}$. Esses doadores são, em geral, grandes marcas alimentícias e redes globais de restaurantes, como é o caso da Yum! - proprietária de marcas como PizzaHut, que só em 2011 doou, individualmente, mais de US\$ 57 milhões de dólares ao Programa (WFP, 2013).

As organizações filantrópicas globais, em geral, "braços sociais" de grandes impérios corporativos, também são instrumentos de influência das empresas nas agendas de organismos internacionais da alimentação, agricultura e nutrição. Entidades como a Bill \& Melinda Gates e a Rockerfeller Foundation, são alguns dos principais responsáveis pelo aumento no volume de repasses de recursos privados à agenda da ONU. De 2003 a 2014, a Bill \& Melinda repassou mais de US\$ 362 milhões de dólares a projetos de desenvolvimento agrícola tocado por organizações internacionais (MARTENS e SEITZ, 2015, p.44). Essas injeções financeiras cumprem ação coordenada em outras frentes da ONU, já que também se estendem à agenda da saúde - intimamente ligada à alimentar e nutricional - como demonstra a posição da entidade filantrópica do grupo Microsoft como segunda maior doadora da Organização Mundial da Saúde (OMS), atrás apenas dos EUA (ADAMS e LUCHSINGER, 2015).

A formalização de setores específicos para cooperação com as empresas é mais um dos destaques da relação entre Ols e CTNs. No PAM, a instância para cooperação com o setor privado está inserida na Diretoria de Parcerias, Governança e Advocacia. Na FAO, o braço de articulação com as corporações está situado no Comitê de Segurança Alimentar (CSA), órgão que, desde de 2009, após concluída sua reforma institucional, tem sido mencionado como um dos mais democráticos entre os fóruns da ONU (MCKEON, 2013) ${ }^{11}$. Nele, além de ONGs e movimentos

\footnotetext{
${ }^{10}$ De 1998 a 2000, as doações de origem privada para o PAM levavam a origem por país ou tipo de entidade doadora (ex. "Private Donors (Japan ONGs)"), a partir de 2001, as doações privadas passam a estar nomeadas simplesmente por "Private Donors", o que impede uma identificação precisa da origem e natureza do doador privado.

11 A reforma do Conselho de Segurança Alimentar da ONU (CSA) instituiu que, além do reconhecimento de membros-plenos, os movimentos sociais e ONGs pudessem intervir nos debates como qualquer delegação; estivessem em categoria separada do setor privado (o que não ocorre em fóruns que costumam mesclar diferentes atores não estatais como "sociedade civil"); que as decisões ocorram em assembleia, que os governos devem formalizar as decisões (assumindo responsabilidades), que as organizações campesinas têm direito à autodeterminação, podendo contar com as ONGs na condição de "apoiadoras", mas não representantes de suas demandas, entre outras medidas. Nora Mckeon atribui grande responsabilidade por essa abertura institucional à
} 
campesinos transnacionais, as corporações têm assento permanente na divisão conhecida como Mecanismo do Setor Privado (Private Sector Mechanism - PSM). Representadas pela International Agri-Food Network, multinacionais como Bayer, Syngenta, Yara International e Monsanto emitem suas posições sobre os mais variados temas da governança agroalimentar e nutricional. No quadro 1 (ver abaixo) listam-se algumas das principais corporações e associações empresariais que participaram ou apoiaram (institucional ou financeiramente) as atividades do PSM em 2017. É interessante observar que, além de majoritariamente formado por corporações e suas entidades representativas, quase $95 \%$ do quadro de membros do PSM é composto por entidades sediadas em países centrais.

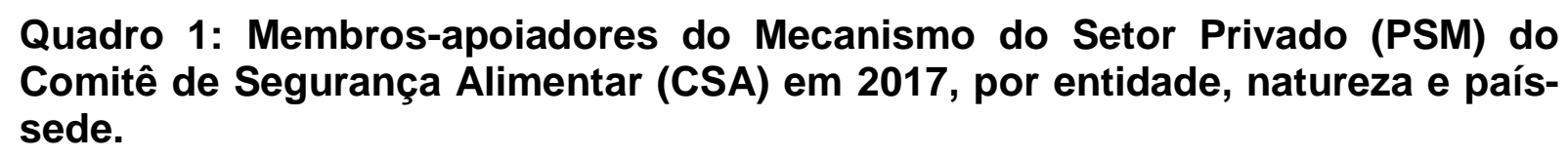

Quadro 1: Membros-apoiadores do Mecanismo do Setor Privado (PSM) do Comitê de Segurança Alimentar (CSA) em 2017, por entidade, natureza e paíssede.

\begin{tabular}{|l|l|l|}
\hline Entidade: & Natureza: & Sede: \\
\hline Abbott Laboratories & Corporativa & Estados Unidos \\
\hline Amway & Corporativa & Estados Unidos \\
\hline Bayer CropScience AG & Corporativa & Alemanha \\
\hline Canon Garth & Corporativa & Reino Unido \\
\hline Canadian Canola Growers Association (CCGA) & Associação Empresarial & Canadá \\
\hline Cargill & Corporativa & Estados Unidos \\
\hline CropLife International (CLI) & Corporativa & Bélgica \\
\hline Cultivating New Frontiers in Agriculture (CNFA) & Agência de & Estados Unidos \\
& Desenvolvimento & \\
\hline Danone & Corporativa & França \\
\hline Danone - Early Live Nutrition & Corporativa & França \\
\hline ePure & Associação Empresarial & Bélgica \\
\hline Export Trading Group & Corporativa & Tanzânia \\
\hline Global Dairy Platform (GDP) & Associação Empresarial & Estados Unidos \\
\hline Global Farmer Network & Associação Empresarial & Estados Unidos \\
\hline Global Pulse Confederation (GPC) & Associação Empresarial & Emirados Árabes Unidos \\
\hline Grain and Feed Trade Association & Associação Empresarial & Reino Unido \\
\hline Health for Animals & Agência governamental & Reino Unido \\
\hline Himalayan Apple Growers (HAGS) & Associação Empresarial & Índia \\
\hline International Chamber of Commerce (ICC) & Associação Empresarial & França \\
\hline International Dairy Federation & Associação Empresarial & Bélgica \\
\hline International Fertilizer Association (IFA) & Associação Empresarial & França \\
\hline International Food and Beverage Alliance & Associação Empresarial & Bélgica \\
\hline & & \\
\hline
\end{tabular}

coordenação dos movimentos rurais através do Comitê Internacional de Planejamento em Soberania Alimentar (McKEON, 2017, p.75-79). 


\begin{tabular}{|l|l|l|}
\hline (IFBA) & & \\
\hline International Seed Federation (ISF) & Associação Empresarial & Suíça \\
\hline Longevity Development Holdings Limited & Corporativa & Reino Unido \\
\hline Mars Inc. & Corporativa & Estados Unidos \\
\hline M ead Johnson & Corporativa & Estados Unidos \\
\hline M onsanto & Corporativa & Estados Unidos \\
\hline Nuffield International & Filantrópica & Reino Unido \\
\hline Piscari Industries & Corporativa & Austrália \\
\hline Sight \& Life Foundation (DSM) & Filantrópica & Suíça \\
\hline Syngenta & Corporativa & Suíça \\
\hline Tetra Laval & Corporativa & Suíça \\
\hline U.S. Council for International Business & Associação Empresarial & Estados Unidos \\
\hline U.S. Soybean Export Council (USSEC) & Associação Empresarial & Estados Unidos \\
\hline Vestergaard & Corporativa & Suíça \\
\hline Yara International & Corporativa & Noruega \\
\hline
\end{tabular}

Fonte: Internacional Agri-food Network (2018). Elaboração do autor.

Embora no caso do FIDA não tenha sido localizada uma instância semelhante ao Mecanismo do Setor Privado, o Fundo geralmente publica estratégias de cooperação com o setor privado na forma de relatórios, como é o caso do intitulado Private Sector Strategy: deepening IFAD's engagement with the private sector, no qual a instituição justifica seus interesses nessa modalidade de cooperação: "(...) o interesse do IFAD em aprofundar seu engajamento com o setor privado é guiado pela necessidade de catalisar investimentos, recursos, conhecimentos, tecnologia e serviços adicionais, além de acesso a mercados para a população rural pobre" (IFAD, 2012, p.9, tradução nossa).

Outra forma encontrada pelas organizações internacionais para estreitar laços com as CTNs tem sido o incentivo às "práticas corporativas sustentáveis". Encorajar a implementação de "negócios sustentáveis incorporados em programas de responsabilidade social corporativa (CSR)" é um dos objetivos perseguidos pela FAO, por exemplo (FAO, 2013, tradução nossa). Mas o que ganham as corporações associando suas práticas socialmente sustentáveis à agenda das organizações internacionais? Embora não seja tarefa razoável medir em termos quantitativos os benefícios dessas parcerias para o setor privado, para Buse e Walt (2000), elas tendem a repercutir no i) aumento da influência empresarial nos processos de tomada de decisão públicos (nacionais e internacionais); convertem-se em ii) benefícios financeiros indiretos (como isenção fiscal, acesso a mercados, etc.); e no 
iii) fortalecimento da autoridade e legitimidade desses atores (privados) enquanto produtores normativos, por sua associação com as instâncias públicas internacionais.

O próprio PAM reforça o argumento acima afirmando que "94\% dos consumidores tendem a comprar de marcas que possuem 'consciência social"' (WFP, 2018b, tradução nossa). Este tipo de cooperação tem como um de seus aspectos mais característicos o empréstimo da imagem das organizações internacionais às campanhas de marketing das empresas, que utilizam dessa associação para reforçar sua legitimidade como atores comprometidos com as demandas socioambientais. O CEO da rede MasterCard, a quem o PAM atribuiu o Prêmio de Herói da Fome (Hunger Hero Award) durante o Fórum Econômico de Davos, em 2017, diz para o site do Programa que "causas sociais não são responsabilidade apenas de governos, agências de ajuda e organizações de caridade" (WFP, 2017b, tradução nossa), chamando a atenção para o papel do setor privado em atender, tais como os Estados, parcela das demandas públicas por segurança alimentar e nutricional.

As parcerias-público-privadas para a oferta de produtos e/ou serviços também tem servido como plataforma de entrelaçamento entre as agendas das organizações agroalimentares e as corporações do setor. O FIDA oferece um exemplo desse tipo de articulação através do chamado Public-Private-Producer Partnerships (4Ps), um programa estabelecido pela agência com o propósito de integrar pequenos e médios produtores rurais às cadeias de valor do agronegócio global $^{12}$. Programas dessa natureza, em apoio à modalidade de agricultura por contrato (contract farming) ${ }^{13}$, têm se tornado uma das grandes bandeiras dessas

\footnotetext{
12 Segundo o relatório How to do Public-Private-Producer Partnerships (4Ps) in Agricultural Value Chains, publicado pelo Fundo em março de 2016, o modelo de funcionamento do 4Ps, em tese, diverge das já conhecidas parcerias-público-privadas por nutrir características como: I) monitoramento sistemático e avaliação de resultados; II) alta seletividade dos parceiros privados com base em critérios de competitividade, transparência e objetividade; III) pelo papel ativo dos produtores tanto na negociação como na governança e monitoramento; IV) no compartilhamento de responsabilidades e benefícios; V) no tempo de vida dos projetos - que se orientam sob uma "business logic" (IFAD, 2016).

${ }^{13}$ Dentro do esquema de contract farming, ou agricultura por contrato, o investidor estrangeiro oferece ao pequeno/médio produtor um contrato de compra da produção (geralmente a preço fixo) previamente a sua colheita, enquanto a titularidade da propriedade rural segue em nome deste último, que usa de seus fatores de produção e insumos para entregar os produtos demandados em quantidade e prazo negociados com o investidor.
} 
organizações no que diz respeito a uma integração "sustentável" entre pequenos agricultores e investidores internacionais.

Por razões estratégicas já mencionadas, a produção normativa é um dos principais elementos a atrair a participação das corporações para a agenda das organizações internacionais. Percebe-se um interesse particular das CTNs em tencionar pela promoção de enfoques pró-mercado de regulação, dos quais os exemplos mais expressivos são os códigos de conduta e boas práticas. Essa tendência tem seguido os principais processos de concertação internacionais recentes, como no caso da elaboração e debate em torno dos Principles For Responsible Agricultural Investiments (PRAI), uma versão prévia dos já mencionados RAI. o PRAI, que consistiu em um conjunto de 7 princípios elaborados pela FAO, o Banco Mundial, o FIDA e a UNCTAD, em 2010, sob demanda do Grupo dos 7 (G7) e em resposta ao fenômeno das aquisições transnacionais de terras e seus efeitos catastróficos sobre pequenos produtores e povos tradicionais da periferia. $O$ documento, quando lançado, apostava na transformação da natureza dos investimentos agrícolas de larga escala, de "riscos" em "oportunidades" ao desenvolvimento rural (STEPHENS, 2011, p.15; UNCTAD, 2017). Apoiado por Estados Unidos, Canadá, Austrália, e, claro, pelas corporações reunidas sob o guarda-chuva do "Setor Privado", ele demandava um enfoque pragmático, autoregulatório e bussiness-likely para a regulação do fenômeno da apropriação de terras (MCKEON, 2013, p.115).

\subsection{Contradições da influência corporativa sobre a agenda agroalimentar da ONU}

Se, como costumam lembrar alguns ideólogos, "não existe almoço grátis", as contribuições financeiras mobilizadas por entes capitalistas (empresas e suas fundações filantrópicas) às organizações internacionais, não são orientadas por princípios meramente morais - caso das doações individuais realizadas por assalariados, por exemplo. Elas respondem, na verdade, a interesses estritamente político-econômicos. Para Morvaridi (2012), no que toca à agenda agroalimentar, tais contribuições teriam como objetivo reduzir a centralidade dos Estados nas 
políticas de segurança alimentar, reforçar a autoridade privada das corporações nessas políticas e permitir que essas possam trocar capital econômico por "capital simbólico" (e vice-versa), ou, em outros termos, transformar os atributos de seu poder estrutural e instrumental em mecanismos de autoafirmação de seu poder discursivo, canalizando os resultados dessa autoafirmação para a geração de novos ganhos econômicos.

Além disso, através das inversões financeiras aos orçamentos e programas das organizações internacionais, as CTNs buscariam angariar apoio institucional público para projetos essencialmente privados, como é o caso da AGRA (Alliance for a Green Revolution in Africa), iniciativa articulada pela Gates e a Rockerfeller Foundation, com mesa diretora composta pelo próprio Koffi Annan, que tem como um de seus principais alvos a agricultura africana. Finalmente, o suporte financeiro às Ol's serve ao arcabouço discursivo que legitima a expansão da agricultura comercial de larga escala nos países do Sul global como projeto de desenvolvimento rural, a despeito de seus efeitos negativos sob o ponto de vista socioeconômico e ambiental.

Embora comumente celebrado como parte da "democratização" das organizações internacionais, do sistema ONU e, mais ambiciosamente, da política internacional, a criação de espaços oficias para o diálogo com as corporações sobre a agenda agroalimentar e nutricional é outro ponto problemático. Conti (2016) descreve que nos últimos processos de concertação intergovernamentais, tem-se frequentemente outorgado ao setor privado a mesma representação atribuída aos movimentos sociais transnacionais - representantes de pequenos agricultores, povos indígenas, pescadores, pastores, etc.

O suposto apelo por isonomia entre os stakeholders da governança global agroalimentar, no entanto, ofusca as assimetrias que permitem, por exemplo, que as corporações frequentem muito mais assiduamente os debates e deliberações políticas sediadas em instâncias como o Comitê de Segurança Alimentar, que os movimentos representantes daqueles afetados pelas atividades dessas mesmas corporações, os quais enfrentam, em geral, sérias restrições de ordem orçamentária e logística, além de não possuírem o mesmo acesso facilitado às chancelarias dos 
governos, como têm as empresas, portanto, gozam de menor capacidade de influenciar nas decisões políticas (CONTI, 2016, p.9)

Além disso, contraditoriamente às concessões e cobranças feitas por novos espaços de expressão, as corporações transnacionais frequentemente se engajam na prática de mudança de fórum (fórum-shifting), que consiste em migrar entre instâncias (neste caso, espaços institucionais da ONU) com o objetivo de evitar normas vinculantes sobre sua atuação ou utilizando-se unilateralmente daquelas agências que melhor convergem ou representam seus interesses e ideologias (SELL, 2009, p.203). O apoio das corporações à liderança do Banco Mundial, em detrimento do Comitê de Segurança Alimentar - reconhecidamente mais democrático que o próprio BM em sua estrutura decisória, diga-se de passagem - e de uma abordagem centrada nos direitos humanos para lidar com os investimentos agrícolas de larga escala, como ocorrido no período anterior às negociações das Diretrizes Voluntárias sobre a Governança da Posse de Terra ${ }^{14}$, demonstra que os atores corporativos estão menos preocupados com o conteúdo democrático das organizações internacionais, e mais com o emprego utilitário que podem fazer delas no processo de legitimação de suas próprias agendas.

As nuances da Responsabilidade Social Corporativa como parte integrante da estratégia de associação da agenda agroalimentar com as empresas também são muitas. Uma delas é que as corporações frequentemente utilizam da aproximação com agências como a FAO e o PAM para praticar bluewashing, estratégia que consiste em apresentar-se como socialmente responsável mediante envolvimento com iniciativas da ONU - a exemplo do Pacto Global - mesmo estando paralelamente implicadas em processos de violação de direitos humanos (ARAGÃO, 2010). Nestes casos, ao emprestar sua imagem às corporações, as Ols acabam incorrendo em alto risco de legitimidade política. Para ilustrar como tais riscos podem se apresentar, tomemos o caso do FIDA e a Aliança do G8 para

\footnotetext{
${ }^{14}$ Apesar de ter avançado questões importantes, as negociações, ironicamente presididas pelos Estados Unidos, longe de constituírem uma moratória contra a estrangeirização de terras (como queriam a princípio parcela dos movimentos sociais), culminou na aprovação de um documento não vinculante, ou seja, voluntário, e com a garantia de que as discussões em torno dos PRAI seguiriam após adoção das Diretrizes, o que respondia, em paralelo, aos objetivos dos interessados nos grandes acordos de aquisição de terras: Estados, corporações e grupos financeiros internacionais.
} 
Segurança Alimentar e Nutricional (G8 Alliance for Food Security and Nutrition) ${ }^{15}$. 0 Fundo é um dos apoiadores da iniciativa que, desde lançada, em 2012, é reconhecida por representar séria ameaça de expulsão e deslocamento de milhões de famílias rurais pobres nos países africanos alvos de investimentos agrícolas (ACTIONAID, 2015). A Nestlé, que integra a Aliança e promete investir mais de 40 milhões de dólares até 2020 em projetos voltados a pequenos produtores da Costa do Marfim, recentemente confessou, após inúmeras denúncias e pressão da opinião pública, que sua cadeia de suprimentos na Tailândia utilizava-se de trabalho escravo. Ao mesmo tempo, nos Estados Unidos, o conglomerado suíço é indiciado por uso de trabalho infantil em fazendas de cacau na própria Costa do Marfim onde pretende investir (THE GUARDIAN, 2016).

O desinteresse por assumir riscos produtivos é também uma marca do papel exercido pelas corporações na governança agroalimentar. Projetos como os $4 P S$ do FIDA, ilustram a aversão dos capitais aos riscos inerentes aos investimentos produtivos, que preferem contar com pesados investimentos públicos iniciais antes de fechar contratos ${ }^{16}$. Embora se coloquem como "inovadoras", tais iniciativas, que contam com os chamados brokers, já são razoavelmente conhecidas por, em geral, circunscreverem os agentes públicos a papéis secundários, de facilitadores, coordenadores ou de garantidores jurídicos dos benefícios sobre os planos de negócios e sobre o capital aplicado por investidores (GREGORATTI, 2010, p.200). Além do uso extensivo de recursos públicos em iniciativas que beneficiam majoritariamente entidades privadas, PPPs como os 4Ps são questionáveis do ponto de vista dos impactos sociais que podem inferir através da integração de pequenos agricultores às concentradíssimas cadeias de valor corporativas voltadas ao mercado internacional de commodities agrícolas.

Ainda que falem em "riscos compartilhados" entre membros da cadeia, essas iniciativas tendem a pormenorizar as assimetrias de poder entre produtores e

\footnotetext{
15 A G8 Alliance for Food Security and Nutrition, como indica seu nome original, é uma iniciativa que envolve o clube dos 8 (Estados Unidos, Canadá, Japão, Itália, Reino Unido, Rússia, França e Alemanha), grandes corporações da agroindústria e 10 governos africanos (Benin, Burkina Faso, Costa do Marfim, Etiópia, Gana, Malaui, Moçambique, Nigéria, Senegal e Tanzânia), e tem como um de seus principais objetivos promover investimentos públicos e privados em áreas chave da agricultura africana.

16 O FIDA justifica esse modelo de PPP alegando que ".... uso de recursos públicos é justificável para endereçar uma "falha de mercado", onde os altos riscos e custos transnacionais de trabalhar com pequenos produtores previne empresas privadas de forjarem relações de negócio"(IFAD, 2016, tradução nossa).
} 
investidores. A agricultura por contrato, a despeito de experiências bem-sucedidas, costuma induzir altos custos produtivos a pequenos agricultores, que não raro são forçados a empregar força de trabalho doméstica para atender os requisitos e volume de produtos demandados, o que também implica um forte controle sobre o ritmo e intensidade da produção, levando à perda da autonomia que é chave da resiliência dessas famílias, e conduzindo-as frequentemente ao fenômeno do "assalariamento", quando o trabalhador rural acaba se tornando um empregado em sua própria terra, sem gozar, contudo, das garantias legais a que trabalhadores assalariados geralmente têm acesso (GÓMEZ, 2014, p.93).

\begin{abstract}
A agricultura por contrato ligadas às cadeias corporativas de valor é citada como uma estratégia alternativa onde todos saem ganhando (win-win), mas nem sempre é assim. Os agricultores são submetidos ao controle corporativo sobre o que plantam, quando e como, e portanto perdem a autonomia que é a base de sua resiliência. As cadeias de valor corporativas remuneram a todos mais que ao produtor primário. Noventa e nove por cento da produção mundial de cacau é produzida por cerca de 5.5 milhões de pequenos produtores rurais, os quais recebem menos de $5 \%$ do total do valor de uma barra de chocolate. (OXFAM, 2013, apud McKEON, 2017, tradução nossa).
\end{abstract}

Por fim, uma das mais contraditórias constatações na relação corporativa com a agenda agroalimentar da ONU é a indisposição das corporações por assumir responsabilidades condizentes com o respeito aos direitos humanos. Enquanto conclama participação nos processos de construção de normas que governem as políticas agroalimentares, o setor privado mostra-se simultaneamente insatisfeito até mesmo com tímidas iniciativas de regulação e responsabilização oriundas de espaços como a FAO e o Comitê de Segurança Alimentar, mesmo sendo ele mesmo - o setor privado - o principal defensor dos modelos regulatórios de caráter flexível e voluntários. Demonstração desse sintoma é visível em uma declaração de posicionamento ao CSA sobre as discussões envolvendo os Investimentos Agrícolas Responsáveis emitida pelas corporações em abril de 2014, quando, através do Mecanismo do Setor Privado (PSM), seus representantes se queixaram do que chamaram de uma "floresta de diretrizes e princípios" em referência aos princípios e diretrizes elaborados nos últimos anos, e na suposta imprecisão dos conceitos e responsabilidades atribuídas às empresas nestes documentos (INTERNATIONAL AGRI-FOOD NETWORK, 2014, tradução nossa). 


\section{Considerações finais}

As últimas décadas experimentaram um aprofundamento da relação entre as corporações transnacionais e a agenda de desenvolvimento e direitos humanos da ONU. No que toca à governança da agricultura, alimentação e nutrição, a influência corporativa perpassa o paradigma hegemônico de segurança alimentar e se torna ainda mais visível na crescente relevância da contribuição privada aos orçamentos, atividades e projetos das agências especializadas, no fomento às iniciativas de responsabilidade corporativa, na formulação de parcerias-público-privadas e na produção de instrumentos de regulação pró-mercado. As incoerências também são notáveis e se manifestam no interesse ambíguo das corporações pelas estruturas "democráticas" de decisão na ONU, no apoio das agências a consórcios corporativos, marcas "socialmente responsáveis" e projetos de integração de pequenos agricultores às cadeias globais da agroindústria.

Ao longo do artigo, mostrou-se como cada uma dessas tendências se associa, paralelamente, a efeitos nefastos produzidos pela experiência prática de atuação dessas corporações, principalmente nos países pobres, onde protagonizam graves violações de direitos humanos, episódios de êxodo rural forçado, estratégias de bluewashing e, mais estruturalmente, fomentam um modelo agroexportador altamente concentrado e responsável por profundos impactos sobre o meio ambiente, incluindo a sobre-exploração dos recursos hídricos, a salinização e declínio da fertilidade das terras agrícolas, sua compactação e poluição, e a progressiva destruição de sua biodiversidade. Do ponto de vista político, tais incoerências reforçam o argumento de que, a despeito do crescente interesse corporativo pela agenda agroalimentar global, ou apesar dos constrangimentos que são capazes de provocar nos Estados e organismos internacionais mediante seu poder instrumental, estrutural e discursivo, as CTNs mostram-se pouco inclinadas a assumir responsabilidades condizentes com as capacidades econômicas e políticas acumuladas por elas.

Este trabalho baseou suas conclusões exclusivamente no contexto da influência corporativa nas políticas agroalimentares sediadas por três organizações do sistema ONU. Por essa razão, ele constitui um esforço intelectual que apenas 
apreende uma dimensão parcial do processo. Outras agendas de pesquisa demonstram enorme potencial de oxigenação desse campo de investigação. A título ilustrativo, considera-se o caso da proposta de um Tratado Internacional Vinculante sobre Empresas e Direitos Humanos, em tramitação no Conselho de Direitos Humanos da ONU (Genebra) desde 2014 e abertamente contestado por Estados Unidos e as corporações. Soma-se a isso temas como a governança das aquisições transnacionais de terras (MARGULIS, et al. 2013; ARAGÃO e SANTOS, 2017), o processo de formulação e negociação da agenda 2030 da ONU (ARAGÃO e SANTOS NETO, 2015) e as primeiras consequências da Aliança do G8 sobre a segurança alimentar de famílias rurais africanas (OXFAM, 2014; PATEL et al. 2015).

Em conjunto, tais agendas de pesquisa, mais que um quadro novo de nuances, dinâmicas e problemáticas em torno do papel das empresas na globalização, servem à denúncia e ao reforço da natureza eminentemente política que fundamenta a governança global neoliberal, aspecto que, além de contrariar certo apelo tecnocrático que costuma dominar as abordagens em torno dessa esfera, é indispensável à formulação de análises verdadeiramente críticas sobre o significado dos processos de democratização da ordem mundial contemporânea.

\section{Referências}

ACTIONAID. New Alliance, New Risk os Land Grabs: evidence from Malawi. 2015. Disponível em: http://www.actionaid.org/sites/files/actionaid/new alliance new risks of land grabs. pdf > Acesso em 22/05/2017.

ADAMS, Barbara; LUCHSINGER, Gretchen. Fit for whose purpose?. Global Policy Watch. 2015. Disponível em: <https://www.globalpolicywatch.org/blog/2015/07/27/fitfor-whose-purpose/> Acesso em 20 de Outubro de 2017.

ALEM, Daniel; OLIVEIRA, Gilca G; OLIVEIRA, Jaqueline. IMBIRUSSÚ, Érica. Segurança Alimentar e Soberania Alimentar: construção e desenvolvimento de atributos. XX Encontro Nacional de Economia Política, Foz do Iguaçu, 2015. 
ARAGÃO, D.M.C. Responsabilidade como Legitimação: capital transnacional e governança global na Organização das Nações Unidas. Tese (Doutorado). Rio do Janeiro: PUC-Rio, 2010.

; SANTOS NETO, M. J. A Agenda Pós-2015 de Desenvolvimento da ONU: aprofundamento da virada neoliberal? Anais Eletrônicos do $5^{\circ}$ Encontro Nacional da Associação Brasileira de Relações Internacionais, Belo Horizonte, 2015.

; SANTOS, T.M. A governança global do desenvolvimento e a despolitização do land grabbing: "there is no alternative"? Estudos Internacionais, v.5, n.2, p.57-73, 2017.

BULL, Benedicte; MCNEILL, Desmond. From Business Unusual to Business as Usual: The Future Legitimacy of Public-Private Partnerships with Multilateral Organizations. In. BEXELL, Magdalena; ULRIKA, Mörth (Org.). Democracy and Public-Private Partnerships In Global Governance. New York: Palgrave Macmillan, 2010, p.190-210.

BUSE, K; WALT, G. Global Public Private Partnerships: Part II-what are the health issues for global governance? The International Journal of Public Health, v.78, n.5, p.699-709, 2000.

CLAPP, Jennifer; FUCHS, Doris. Agrifood corporations, Global Governance, and Sustainability: a framework for analysis. In (org.). Corporate Power in Global Agrifood Governance. London: The MIT Press, 2009, p.1-25.

; ISAKSON, S. Ryan. Risky Returns: The Implications of Financialization in the Food System. Development and Change, v.49, n.2, p.437-460, 2018.

CONTI, Mauro. Food sovereignty agenda of transnational rural social movements in the UN global governance. Global governance/politics, climate justice \& agrarian/social justice: linkages and challenges (Colóquio), International Institute of Social Sciences, Haia, 2016.

COX, Robert W. Gramsci, Hegemony and International Relations: An Essay in Method. Millennium, v. 12, n.2, p.162-175, 1983.

Structural issues of global governance: implications for Europe. In: GILL, Stephen (Org.). Gramsci, Historical Materialism and International Relations. New York: Cambridge University Press, 1993, p.259-289.

DE SHUTTER, Olivier. Adressing Concentration in Food Supply Chains: the Role of Competition Law in the Tackling the Abuse of Buyer Power. 2010. Disponível em: < http://www.srfood.org/images/stories/pdf/otherdocuments/20101201 briefing-note03 en.pdf> Acessado 23 de abril de 2017.

ECONEXUS. Agropoly: a handful of corporations control world food production. 2013. Disponível em: <http://www.econexus.info/publication/agropoly-handfulcorporations-control-world-food-production> Acessado em 20 de abril de 2017. 
FAO. Fao strategy for parterships with the private sector. 2013. Disponível em: < http://www.fao.org/partnerships/private-sector/en/> Acessado em 18 de abril de 2017.

Food Security (policy brief). 2006. Disponível em:< http://www.fao.org/forestry/13128-0e6f36f27e0091055bec28ebe830f46b3.pdf> Acessado em 13 de dezembro de 2016.

FONTOURA, Yana; BHARUCHA, Zareen P; BÖHM, Steffen. A transnational agrifood system for whom? The struggle for hegemony at Rio+20. RAE, v. 56, n.4, p.424-437, 2016.

GILL, Stephen. Hegemony, Consensus and Trilateralism. Review of International Studies, v.12, n.3. p. 205-221, 1986.

. Globalization, Market Civilization, and Disciplinary Neoliberalism. Millennium: Journal of International Studies, v.24, n.3, p.399-423, 1995.

Global Structural Change and Multilateralism. In: .(Org.). Globalization, Democratization, and Multilateralism. New York: Palgrave MacMillan, 1997, p.1-17.

GÓMEZ, Sergio. The land Market in the Latin America and the Caribbean: concentration and foreignization. Santiago: FAO. 2014.

GREGORATTI, Cátia. UNDP, Business Partnerships, and the (UN)Democratic Governance of Development. In: BEXELL, Magdalena; ULRIKA, Mörth (Org.). Democracy and Public-Private Partnerships in Global Governance. New York: Palgrave Macmillan, 2010, p.190-210.

IFAD. Private Sector Strategy: deepening engagement with the private sector. 2012. Disponível em: <https://www.ifad.org/documents/10180/aeb5f367-af87-46b1-9419355562b1dbc0 > Acessado em 17 de maio de 2017.

. How to do Public-Private-Producer Partnerships (4Ps) in Agricultural Value Chains. 2016. Disponível em < https://www.ifad.org/documents/10180/998af683200b-4f34-a5cd-fd7ffb999133> Acessado em 25 de março de 2017.

INTERNATIONAL AGRIFOOD NETWORK. Position paper response. 2014. Disponível em: http://www.agrifood.net/position-papers/49-rai-private-sectorstatements-april-2014/file Acessado em 10 de maio de 2017.

Private Sector Mechanism. 2018. Disponível em: https://agrifood.net/private-sector-mechanism. Acessado em 08 de maio de 2018.

MARGULIS, Matias E; McKEON, Nora; BORRAS, Saturnino. Land Grabbing and Global Governance: Critical Perspectives. Globalizations, v.10. n.1, p.1-23. 2013. 
MARTENS, Jens. Corporate influence on the business and human rights agenda of the United Nations. Bonn: Global Policy Forum, 2014.

. SEITZ, Karolin. Philanthropic Power and Development: Who shapes the agenda? Bonn: Global Policy Forum, 2015.

McKEON, Nora. The United Nations and civil society: legitimating global governance-whose voice?. Zed Books, 2009.

. 'One Does Not Sell the Land Upon Which the People Walk': Land Grabbing, Transnational Rural Social Movements, and Global Governance. Globalizations, v. 10, n. 1, p. 105-122, 2013.

. Civil Society-Public Institution Relations in Global Food Policy: The Case of FAO and the CFS. In: MARCHETTI, Raffaele (Org.). Partnerships in International Policy-Making: Civil Society and Public Institutions in European and Global Affairs. Palgrave MacMillan, 2017, p.71-88.

McMICHAEL, Philip. Historizing Food Sovereignty. Journal of Peasants Studies, v.41, n.6, p.933-957, 2014.

. Regimes Alimentares e Questões Agrárias. São Paulo: Editora Unesp; Porto Alegre: Editora da UFRGS, 2016.

MORVARIDI, Behrooz. Capitalist Philanthropy and the New Green Revolution fod Food Security. International Journal of Sociology of Agriculture and Food. V. 19. N. 2. Pp. 243-256. 2012.

MURPHY, Sophia. Land Grabs and Fragile Food Systems: the role of Globalization. 2013. Disponível em: https://www.iatp.org/documents/land-grabs-and-fragile-foodsystems > Acessado em 02 de abril de 2017.

OXFAM. For whose benefit? The G8 Alliance for Food Security and Nutrition in Burkina Faso. 2014. Disponível em http://policypractice.oxfam.org.uk/publications/for-whose-benefit-the-g8-new-alliance-for-foodsecurity-and-nutrition-in-burkin-317049> Acessado em 12 de abril de 2017.

PATEL, Raj. KERR, Rachel B. SHUMBA, Lizzie. DAKISHONI, Laifolo. Cook, Eat, Man, Woman: understanding The New Alliance Food Security And Nutrition, nutritionism and its alternatives from Malawi. The Journal of Peasants Studies. v. 42, n.1, pp. 21-44, 2015.

RICHTER, Judith. Public-private Partnerships for Health: A trend with no alternatives? Development, n.47, v.2, p.43-48, 2004.

ROBINSON, William. Gramsci and Globalization: from nation-state to transnational hegemony. Critical Review of International Social and Political Philosophy. v. 8, n.4, pp.559-574, 2005. 
ROSSET, Peter. Food Sovereignty: global rallying cry of farmer movements. Backgrounder. v. 9, n.4, 2003.

RUGGIE, John. "Global Markets and Global Governance: The Prospects for Convergence". In BERNSTEIN, Steven; PAULY, Louis W. (Org). Global Liberalism and Political Order: Toward a New Grand Compromise? New York: State University of New York 2007, p.23-48.

SASSEN, Saskia. Beyond Inequality: expulsions. In: GILL, Stephen (org.). Critical Perspectives on the Crisis of Global Governance: remaining the future. New York: Palgrave Macmillan, 2015, p.69-88.

SHAW, D. John. World Food Security: a history since 1945. New York: Palgrave MacMillan, 2007.

SMYTHE, Elizabeth. In whose interests? Transparency and Accountability in the Global Governance of Food: Agribusiness, the Codex Alimentarius, and the World Trade Organization. In. CLAPP, Jennifer; FUCHS, Doris. (Org.). Corporate Power in Global Agrifood Governance. London: The MIT Press, 2009, p.93-123.

STEPHENS, Phoebe. The global land grab: an analysis of extant governance institutions. International Affairs Review. v.20, n. 1, p.1-21, .2011.

THE GUARDIAN. Nestlé admits slavery in Thailand while fighting child labour lawsuit in Ivory Coast. 2016. Disponível em: < https://www.theguardian.com/sustainablebusiness/2016/feb/01/nestle-slavery-thailand-fighting-child-labour-lawsuit-ivorycoast> Acessado em 10 de junho de 2017.

UNCTAD. The principles for responsible agricultural investments. 2017. Disponível em:< http://unctad.org/en/Pages/DIAE/G-20/PRAI.aspx> Acessado em 19 de abril de 2017.

VIEIRA, Flávia Braga. Via Campesina: um projeto contra-hegemônico? In: SIMPÓSIO LUTAS SOCIAIS NA AMÉRICA LATINA, 3. 2008, Londrina. Anais ... Londrina: $\quad$ GEPAL, 2008. Disponível em: < http://www.uel.br/grupopesquisa/gepal/terceirosimposio/flaviabraga.pdf > Acessado em 14 de junho de 2017.

WFP. Pizza hut and Taco Bell support Wfp Typhoon Pablo response and school meals. 2013. Disponível em: < https://www.wfp.org/news/news-release/pizza-hutand-taco-bell-support-wfp-typhoon-pablo-response-and-school-meals $>$ Acessado em 20 de abril de 2017.

Funding and donors. 2018a. Disponível em: < http://www1.wfp.org/fundingand-donors > Acessado em 12 de janeiro de 2018.

. Private sector. 2018b. Disponível em:<http://www1.wfp.org/private-sector $>$. Acessado em 29 de janeiro de 2018. 
WILLIAMS, Marc. Feeding the World? Transnational Corporations and the Promotion of Genetically Modified Food. In. CLAPP, Jennifer; FUCHS, Doris. (Org.). Corporate Power in Global Agrifood Governance. London: The MIT Press, 2009, p.155-185.

Recebido em 04/03/2018.

Aprovado em 15/06/2018. 